\title{
RISK-SENSITIVE FORAGING IN COAL TITS
}

\author{
by
}

\author{
LUIS M. BAUTISTA ${ }^{1)}$, BEATRIZ MARTIN, LAURA MARTINEZ \\ and CAROLINA MAYO ${ }^{2)}$ \\ (Departamento de Ecología Evolutiva, Museo Nacional de Ciencias Naturales, CSIC, José \\ Gutierrez Abascal 2, 28006 Madrid, Spain)
}

(Acc. $20-\mathrm{X}-2000)$

\begin{abstract}
Summary
Current theory of risk-sensitive foraging predicts that foragers should choose feeding sites on the basis of variation in as well as mean reward rate when there is a shortfall in their food supply or a decrease in their energy budget. For a given mean reward delay, they should choose high variance feeding sites if they are running below energy requirement, but low variance sites if they are running above. It has been suggested that the smaller the animal size, the stronger the preference reversion between high and low variable feeding sites. Previous tests of the energy budget rule when there was time variability have used bird species heavier than $80 \mathrm{~g}$. Hence we tested energy budget rule predictions with coal tits Parus ater, a bird of $9 \mathrm{~g}$ of body mass, foraging at two feeding sites with high or low variability in food delivering delay. We manipulated energy budgets by controlling air temperature in the laboratory. In one treatment (positive budget), individuals were allowed to eat at the level of their own ad-libitum daily consumption and the air temperature was set to $24^{\circ} \mathrm{C}$, while for the other treatment (negative budget), temperature was set to $14^{\circ} \mathrm{C}$, and food availability was limited to the maximum daily intake observed in the positive budget treatment. When air temperature was low, daily intake increased but body mass decreased. Birds were also less active in the low temperature treatment, hopping less times every day. Latency to peck decreased as well, pecking for food when it was available sooner than in the high temperature treatment. These results show that coal tits were living in a negative energy budget when air temperature was set to $14^{\circ} \mathrm{C}$. Preference for the variable feeding site was greatest in the
\end{abstract}

1) Corresponding author; current address: Instituto de Investigación en Recursos Cinegéticos (IREC), CSIC-VCLM, Spain; e-mail address: 1mbautista@mncn.csic.es

2) We thank Alex Kacelnik for his comments on a previous version of the manuscript and an anonymous referee for useful comments and constructive criticism. This study was funded by project PB95-0102-CO2-01. LMB was supported by a postdoctoral contract from Ministerio de Educación y Ciencia. 
negative energy budget, as it was predicted by the energy budget rule. Contrary to the energy budget rule, coal tits consistently preferred the variable option also in the positive energy budget. Possible explanations for these results are explored, including alternative foraging models to the energy budget rule.

Keywords: energy budget, risk-sensitive foraging, coal tit, Parus ater, optimal foraging, foraging behaviour, time discounting, decision making.

\section{Introduction}

Small birds often experience large daily fluctuations in body mass. This is especially the case of small birds living in environments where food availability changes frequently during the day. They should make frequent decisions concerning where to forage, paying attention not only to the mean expected food availability, but also to the variance around the mean food availability. This concept has been called 'risk sensitivity' (Caraco et al., 1980), a term borrowed from economic theory (Stephens, 1981).

Caraco (1980) proposed an energy budget rule for birds faced with decisions concerning foraging options with identical means of food intake rates but different variances, or levels of risk. This rule states that when faced with an energy surplus, an animal may exhibit risk-averse behaviour; that is, it should not gamble and should choose the low variance foraging option. However, if faced with an energy deficit, the animal should exhibit riskprone behaviour; that is, gamble by foraging in the high variance foraging option, taking a chance of encountering the favourable side of the distribution (Stephens, 1981).

There are two sources of variability in regard with the food intake rate: the amount of food available and the time delay associated with obtaining the food. Both sorts of variability may act combined. Most studies have analysed risk-sensitive behaviour when variability was in amount of food (66\% of 61 studies, see review in Kacelnik \& Bateson, 1996), but only 19 of these manipulated the energy budgets of the subjects. When variability was in delay to obtain food, only six studies manipulated the energy budgets of the subjects. These few experiments in delay variability have met with failure to demonstrate convincing shifts in preference towards the risk-averse alternative or at least a significant difference of a negative energy budget vs. a positive energy budget towards the option with higher variability (Kacelnik 
\& Bateson, 1996). Thus, there is a little direct evidence that energy budget affects risk sensitivity when variability is in delay to receive food.

It has been suggested that the smaller the animal size, the stronger the effect of the energy budget rule (i.e. preference reversion between high and low variable feeding sites depending on energy budget), because light species with few reserves might be more likely to have been subject to selection for short-fall minimization and thus energy budget-associated switches in risksensitivity. All studies about the energy budget rule with variability in delay were conducted on medium-size species of birds such as pigeons, starlings or jays (mean body mass of 143 g, range 82-354 g, see Fig. 3 in Kacelnik \& Bateson, 1996), but they failed to show a significant preference reversal (Kacelnik \& Bateson, 1996). Thus it is not clear at present whether energy budget may have an effect in preference for variability in time to food in small birds. Here we examined energy budget rule predictions with coal tits Parus ater (9 g, Dunning \& Church, 1993). Small passerines such as coal tits have only a limited ability to store energy so a bird deprived of food can probably starve in hours. Since coal tit survival is so crucially related to their success or failure in obtaining sufficient food, it is expected that energy budget should control their preference for variability in delay to food. We tested the energy budget rule in coal tits foraging in the laboratory. Birds obtained equal food rewards from two feeding sites that differed in the delay of food delivering. In one feeding site food was delivered at fixed delays, and in the other feeding site a short delay alternated with a long delay.

Our main aims were to test if a small bird show risk proneness behaviour when there was variability in delay, and to measure the effect size of budget manipulation in accordance with the energy budget rule. We pursued these aims by recording the preferences of coal tits foraging in the laboratory while air temperature was changed to induce positive and negative energy budgets. Another aim was to test a budget-insensitiv e model: the local rate maximization model (Bateson \& Kacelnik, 1996; Bateson \& Whitehead, 1996). This model is based on the assumption that subjects choose alternatives by computing rate of energy gain with an algorithm that yields rate averages per trials rather than per session or longer periods of time, as assumed by classical optimal foraging theory. We applied this model by assuming that birds attribute an expected rate of gain to each option using only the time elapsed between their choice and the respective outcome (Mazur, 1984; Bateson \& Kacelnik, 1996). 


\section{Methods}

(a) Subjects

The subjects were four coal tit Parus ater housed in individual cages measuring $50 \times 40 \times$ $30 \mathrm{~cm}$ arranged such that the birds were visually, but not acoustically, isolated. Birds were living in the experimental cages during six months before the experiment started. Fresh water was always available.

\section{(b) Apparatus}

The experiments were conducted in the birds' home cages. Each cage had two perches, one at each side of the cage, and two food hoppers $(4 \times 3.5 \mathrm{~cm})$ in the cage's back wall. Each food hopper was $10 \mathrm{~cm}$ above the cage floor and the distance between them was $20 \mathrm{~cm}$. Each food hopper had a perch, a bulb light and a pecking key attached. Lights were used to signal what hopper was active and the pecking key recorded the bird's preference. After the pecking key was pressed once, a pellet dispenser (Campden Instruments, Loughborough, UK) delivered in the selected food hopper one food reward. Rewards were made previously by grounding and sieving dry kitten cookies (The IAMS Company, Dayton, Ohio, USA) to small pieces of an even size. One food reward averaged $0.041 \mathrm{~g}$ and took $1 \mathrm{~s}$ to deliver. An Acorn RiscPC-600 microcomputer running Arachnid experimental control language (CeNeS Cognition, 1990) controlled the stimulus events (lights), response contingencies (food hopper selected and food delivery) and recorded the time delay since the food was offered until the coal tit made its food request. We called this period of time as latency to peck.

Temperature in the laboratory was constant and set at $24^{\circ} \mathrm{C}$ before the experiment started. The light-dark cycle was $9: 15$ (L:D), from 0915 hours to 1815 hours. In the day-time period, the lights were brightened and dimmed gradually.

\section{(c) Training}

Birds were induced to peck the response keys by an autoshaping procedure (Staddon, 1983) between 0930 to 1800 hours two weeks before the experiment started. Coal tits initially experienced the delivery of one unit of food preceded by $10 \mathrm{~s}$ of a light in the food hopper. Then an inter-trial interval of $30 \mathrm{~s}$ elapsed until a new unit of food was released with the same procedure. Gradually units of food were delivered conditional on key pecking, keeping the light on until the bird pecked the key. At the end of the training period the birds lived in closed economy (Hursh, 1980; Collier, 1983), obtaining all their food through the experimental schedule. Maximum food delivery could have reached $29.3 \mathrm{~g} /$ day in the training period in this system; twelve times higher than the ad libitum daily intake of $2.3 \pm 0.1 \mathrm{~g} /$ day at $24^{\circ} \mathrm{C}$ of air temperature established prior to this work.

\section{(d) Choice experiment and foraging schedule}

We used a procedure in which birds were repeatedly required to choose between two foraging options that were cued by lights and presented in different foraging sites. One of these sites provided food with a two standard delays ( 0.5 probability each) that remained the same throughout the experiment. In the other foraging site the food was delivered with a single delay adjusted according to the choices made by the bird, getting shorter if the bird preferred 
the standard option, longer if it preferred the adjusting option, and remaining the same if it chose both equally. Based on the assumption that, other things being equal, a bird will prefer to forage at sites where food is obtained faster, the mean delay or indifference point in the adjusting option is thus equivalent to the value of the standard option after some foraging cycles. At the start of this experiment one unit of food was obtained in the standard option after a delay of 3 or $30 \mathrm{~s}$ with a probability of 0.5 , and in the adjusting option after a delay of $1 \mathrm{~s}$. Repeated foraging cycles with the adjusting option being preferred increased the time delay from $1 \mathrm{~s}$ until the adjusting option was equally preferred to the standard option. At the indifference point, time delay in the adjusting option fluctuated in a dynamic equilibrium. Long-term mean rates between inter-trial intervals were predicted to be the same in both foraging options (one food reward every $16.5 \mathrm{~s}$ ), but the expected variance should be greater for the standard option than for the adjusting option.

In this choice experiment risk-sensitive foraging predicts a preference towards highly variable food resources (i.e. the standard option) when energy budget is negative and the reverse if energy budget is positive (Caraco et al., 1980; Kacelnik \& Bateson, 1996). Therefore we predict the mean time delay of the adjusting option would be shorter than $16.5 \mathrm{~s}$ when coal tit's energy budget is negative and longer when coal tit's energy budget is positive.

We used the term trial for describing the events required to obtain a reward. There were 'forced' and 'free' trials. In forced trials only one of the hoppers was active until a reward was collected, so that animals could not choose which hopper to use. A forced trial started with the illumination of the light bulbs of one of the hoppers at random with probability 0.5. After the bird pecked the key at the illuminated hopper and the food was delivered, 20 minutes elapsed (inter-trial interval), and the center key of the other hopper was illuminated. A free trial started with the illumination of both hoppers, allowing the bird to choose the hopper. When the bird pecked one of the center keys, the light of the other hopper was turned off, and one unit of food was delivered after the time appropriate to the selected option. If the standard hopper was chosen first, a unit of food was delivered after $3 \mathrm{~s}$ or $30 \mathrm{~s}$ with 0.5 probability. If the standard hopper was again chosen in the second free trial, the food was delivered with the alternative delay to ensure that both delays were experienced. The two free trials allowed the birds to express their preference for the adjusting or the standard hopper. Four consecutive forced trials formed a forced 'block', and two consecutive free trials formed a free 'block'. A foraging 'cycle' was formed by a forced block followed by a free block (i.e. four forced plus two free trials). In the forced block the bird experienced all current delays of the schedule. To increase the schedule unpredictability, four forced blocks were programmed: A-S-A-L, A-L-A-S, S-A-L-A and L-A-S-A (A for adjusting, S for short standard, and L for long standard delays). These four forced blocks were randomly combined throughout the experiment with a probability of 0.25 each. We called the feeding site with the adjusting option 'fixed' throughout this study because its delay was fixed in a foraging cycle, and the feeding site with the standard option 'variable' because its delay changed.

The delay in the adjusting option was changed with a titration procedure. The adjusting delay was modified by $10 \%$ between cycles, depending on whether, in the two free trials, the bird chose the adjusting hopper (new adjusting delay $=1.10 \times$ old adjusting delay), the standard delay (new adjusting delay $=0.90 \times$ old adjusting delay), or one of each, respectively (new adjusting delay $=1.00 \times$ old adjusting delay). When the old adjusting delay was $\leqslant 9 \mathrm{~s}$, the new adjusting delay was the old adjusting delay $\pm 1 \mathrm{~s}$. The shortest adjusting delay was $1 \mathrm{~s}$. Our procedure permits using the point of equilibrium reached by the animals to determine the equivalence between a variable delay ( 3 and $30 \mathrm{~s}$ with probability 
0.5 ) and an adjusting delay from the tits' point of view. A significant difference in the point of equilibrium between positive and negative energy budgets would be an empirical evidence that the energy budget rule influences the birds' foraging choices.

We continued the titrations for at least 150 foraging cycles. This number of cycles were gathered in 15 days, although some birds needed a few more days. In general visual inspection of the data suggested that the titrations stabilised rapidly. The mean duration of the adjusting delay was calculated with one data point from the last 50 foraging cycles of each individual.

\section{(e) Treatments and energy budgets}

To induce an energy stress we decreased air temperature by $10^{\circ} \mathrm{C}$ from 24 to $14^{\circ} \mathrm{C}$ and removed most bird's mechanisms of cold defense (Dawson \& O'Connor, 1996) such as insulation, behavioural thermogenesis, and endogenous heat production. We first removed insulation, because coal tits were kept in an indoor laboratory. Behavioural thermogenesis was almost completely removed since birds in small cages had no room to fly or to walk. Finally, endogenous heat production was decreased because birds lived in the laboratory during some months before the start of the experiment and their flight and walk muscles were at their minimum size. These muscles are the main source of endogenous heat production by shivering and non shivering mechanisms (Aulie \& Tøien, 1989; Marsh \& Dawson, 1989; Marsh, 1993; Dawson \& O'Connor, 1996). To avoid an increase of energy intake to counterbalance the temperature decrease, maximum daily intake was reduced during the experiment to $3.6 \mathrm{~g} /$ day by stretching the intertrial interval to $20 \mathrm{~min}$ in the experimental periods. After the experiment and before the birds were released, we exercised them in an outdoors aviary until their flight capacity was recovered.

Each treatment lasted 15 days and all birds experienced both treatments. Two birds experienced 15 days at $24^{\circ} \mathrm{C}$ followed by 15 days at $14^{\circ} \mathrm{C}$, while the temperature course was the reverse for the other two birds. Every day we recorded body mass, food intake, and a sample of hopping activity for each bird. Birds were caught at 0915 hours (dawn) and 1800 hours (dusk), and weighed to the nearest $0.01 \mathrm{~g}$. Between four and nine minutes were needed to complete this task. We recorded daily food intake by subtracting spilled food from the weight of dispensed food. The spilled food was collected from the cage floors at 1800 hours. Treatment duration was set to 15 days to prevent body mass decreases greater than $85 \%$.

Activity of birds was sampled in periods of 10 minutes, and it was defined as the the number of hops between perches and cage walls observed in 10 minutes. Coal tits hang on the steel bars of the cage walls, moving repeatly between perches and cage walls. To prevent undue disturbance these data were collected by watching the birds from outside the room through a one-way window. We observed one bird per hour until bird was observed at least once in each hour of daylight in both treatments. Subjects'mean hopping rate was then calculated with 15 sample periods for each treatment.

Latency to peck was recorded in all foraging trials. A mean latency to peck for each birds and treatment was calculatedwith one data point from the last 50 cycles of each treatment. A shorter mean latency was expected at $14^{\circ} \mathrm{C}$ if birds were in a negative energy budget, but a longer mean latency was expecte at $24^{\circ} \mathrm{C}$ if birds were in a positive energy budget.

\section{(f) Model predictions}

Classical optimal foraging theory predicts that an animal will be indifferent between a variable and a fixed delay when the long-term intake rate is the same in both alternatives. 
Because the amount of food delivered per trial was the same in both feeders, the long-term intake rate will be equal when $D_{a}=\left[D_{s}+D_{l}\right] / 2$, where $D_{x}$ is the delay between choice and reward ( $a, s$ and $l$ are, respectively, the adjusting, short and long delays). A delay in the adjusting feeder shorter than the arithmetic mean of the delays in the standard feeder $(16.5 \mathrm{~s})$ would indicate risk-proneness, and a larger delay would indicate risk-aversion with respect to the variable delay (Stephens, 1981; Stephens \& Krebs, 1986).

Local rate maximization model assumes that subjects choose alternatives by computing rate of energy gain with an algorithm that yields rate averages per trials rather than per session or longer periods of time. The two alternatives (fixed and variable) were valued according to the following equations:

$$
V_{f}=\frac{\frac{1}{D_{a}+T}}{1} \quad V_{v}=\frac{\frac{1}{D_{s}+T}+\frac{1}{D_{l}+T}}{2}
$$

where $V_{x}$ is the value attributed to the feeding option $x$ (fixed or variable), $D_{x}$ is the delay between choice and reward ( $a, s$ and $l$ are, respectively, adjusting, short and long delays), and $T$ is the time required to deliver the food ( $1 \mathrm{~s})$. A delay in the fixed feeder not different to $6.1 \mathrm{~s}$ would assign the same value to the fixed and variable feeding alternatives and it would be suggestive that coal tits' decision making could be explained by a local rate maximization model.

Statistical differences between treatments of adjusting delay, hopping rate, and latency to peck were first calculated for each bird with a Student $t$-test. Thereafter whole significance was calculated with a $\chi^{2}$ test of combined probabilities with $2 k$ degrees of freedom, pooling the significance levels of individual $t$-tests $(k=$ number of individual tests, Sokal \& Rholf, 1981). Hopping rate, adjusting delay and latency to peck were log-transformed previously to calculate $t$-tests.

\section{Results}

A relatively small difference of air temperatures was enough to induce an energy budget change. Coal tits body mass decreased when temperature changed from 24 to $14^{\circ} \mathrm{C}$, even though birds increased food intake (Table 1). Figure 1 shows the day-to-day effects of each treatment in body weight. Birds in a negative energy budget lost weight every day (combined simple regression by subjects, Mean $R^{2}=0.76, \chi^{2}=31.0, p=0.001$, df $=8$ ), and slightly increased body mass in positive energy budget (Mean $R^{2}=$ $0.55, \chi^{2}=26.3, p<0.01, \mathrm{df}=8$ ).

Figure 2 shows the average activity rates during the day and the latency to peck in the forced trials in each treatment. As expected, energy budget changed subjects' hopping activity and motivation. Birds moved more when they lived in a positive energy budget (combined paired $t$-tests, $\chi^{2}=26.5$, $p<0.001$, $\mathrm{df}=8$ ), and waited more time to peck once the food was offered 


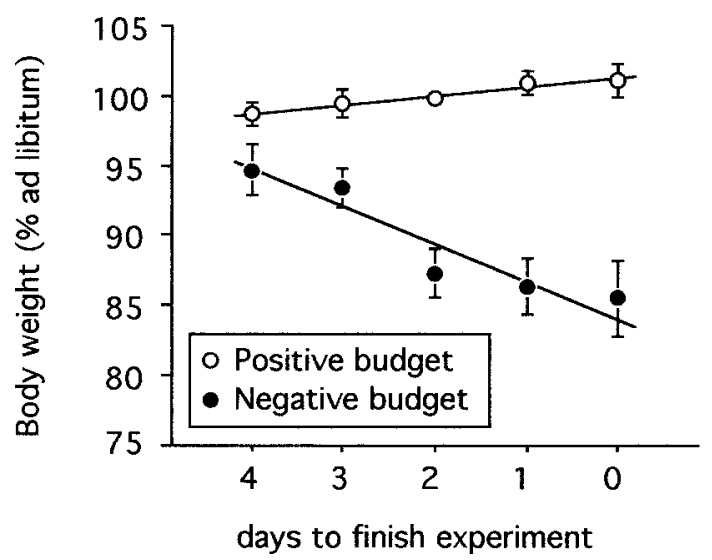

Fig. 1. Mean body weight ( $\pm \mathrm{SE}, N=4$ subjects) expressed as percentage of birds' freefeeding weights under the two treatments in the last 5 days of testing. Body weights decreased in the negative budget treatment and increased slightly in the positive budget treatment.

TABLE 1. Mean daily ( $\pm S D, N=5$ days) food requirements (grams of dry kitten cookies) and free-feeding weight of coal tits kept in temperate $\left(24^{\circ} \mathrm{C}\right)$ and cold $\left(14^{\circ} \mathrm{C}\right)$ air temperatures

\begin{tabular}{|c|c|c|c|c|c|c|c|c|}
\hline \multirow[t]{3}{*}{ Bird } & \multicolumn{4}{|c|}{ Daily food intake (g) } & \multicolumn{4}{|c|}{ Body mass (g) } \\
\hline & \multicolumn{2}{|c|}{ air temperature } & \multirow[t]{2}{*}{$t$} & \multirow[t]{2}{*}{$p$} & \multicolumn{2}{|c|}{ air temperature } & \multirow[t]{2}{*}{$t$} & \multirow[t]{2}{*}{$p$} \\
\hline & $24^{\circ} \mathrm{C}$ & $14^{\circ} \mathrm{C}$ & & & $24^{\circ} \mathrm{C}$ & $14^{\circ} \mathrm{C}$ & & \\
\hline 1 & $1.78 \pm 0.11$ & $2.78 \pm 0.08$ & 16.2 & $<0.001$ & $9.64 \pm 0.06$ & $8.66 \pm 0.66$ & 3.3 & 0.011 \\
\hline 2 & $1.98 \pm 0.15$ & $2.54 \pm 0.11$ & 6.7 & $<0.001$ & $9.60 \pm 0.10$ & $8.60 \pm 0.76$ & 3.0 & 0.021 \\
\hline 3 & $1.78 \pm 0.08$ & $2.14 \pm 0.17$ & 4.3 & 0.003 & $8.94 \pm 0.21$ & $8.18 \pm 0.04$ & 8.0 & $<0.001$ \\
\hline 4 & $1.98 \pm 0.08$ & $2.68 \pm 0.13$ & 11.0 & $<0.001$ & $9.30 \pm 0.07$ & $8.14 \pm 0.30$ & 8.3 & $<0.001$ \\
\hline
\end{tabular}

(combined paired $t$-tests, $\chi^{2}=23.4, p<0.01$, $\mathrm{df}=8$ ). As expected in a titration experiment, there were no significant differences in latency to peck between variable and fixed feeders when energy budget was high (combined paired $t$-tests, $\chi^{2}=0.1, p>0.9, \mathrm{df}=8$ ) and when energy budget was low (combined paired $t$-tests, $\chi^{2}=12.7, p>0.1, \mathrm{df}=8$ ).

Figure 3 shows the mean delay at the equilibrium point for the adjusting option made by each subject under two energy budget conditions. In both treatments the variable feeding site had more value than the fixed feeding site in the coal tit's point of view as shown by the mean adjusting delay. In a negative energy budget all birds showed a shorter delay $(8.5 \pm 1.4 \mathrm{~s}, N=4$ 

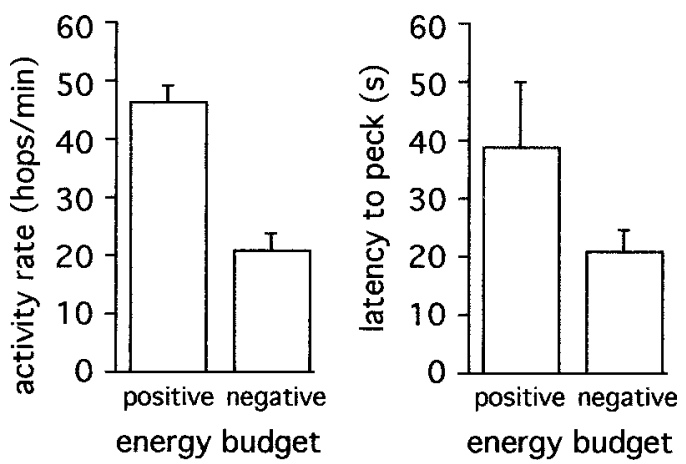

Fig. 2. Mean ( $\pm \mathrm{SE}, N=4$ subjects) number of hops (a) and latency to peck (b) under two energy budget treatments. Coal tits moved less and requested food faster when temperature was $14^{\circ} \mathrm{C}$. Individual sample sizes were 15 and 50 data points for hopping rate and latency to peck respectively (see methods for details).

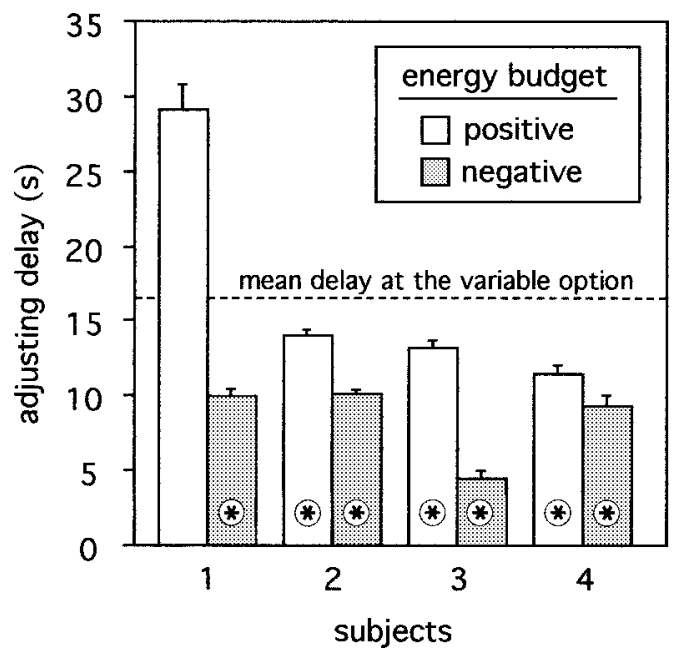

Fig. 3. Mean delay ( \pm SE) at the equilibrium point in the adjusting option of each subject under the two budget conditions. Asterisks mark significant risk proneness (one-sample $t$-tests, $p<0.05, N=50)$.

birds) than the predicted by classical OFT $(16.5 \mathrm{~s}$, combined one-sample $t$ tests, $\chi^{2}=55.3, p<0.001, \mathrm{df}=8$ ). In a positive energy budget only one subject showed a longer adjusting delay than $16.5 \mathrm{~s}$ (bird 1, see Fig. 3, $29.0 \pm$ $1.8 \mathrm{~s}, t=6.9, p<0.01, \mathrm{df}=49$, one sample $t$-test). The other three birds showed a shorter delay than $16.5 \mathrm{~s}$ (see Fig. 3, all $p<0.01$, df $=49$ for each Student $t$-test), and the overall preference was for the variable feeding 


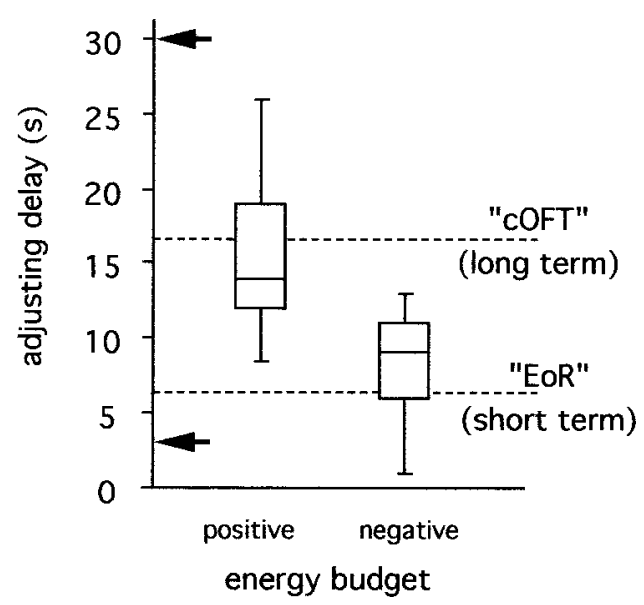

Fig. 4. Box plots of the adjusting delay of four coal tits under positive and negative budget conditions. The two adjusting delays were significantly smaller than the predicted delay by a classic long term rate-maximizing model (long term 'cOFT', Stephens \& Krebs, 1986), but also greater than the predicted delay by a local rate-maximizing model (short term 'EoR', Bateson \& Kacelnik, 1996). The arrows show the delays at the variable feeder (3 and $30 \mathrm{~s}$ ).

site $\left(\chi^{2}=27.6, p<0.01\right.$, df $\left.=8\right)$. Our control over energy budget did change coal tits' preferences reliably, because all birds showed stronger risk proneness under the negative energy budget than under the positive energy budget (combined paired $t$-tests, $\chi^{2}=44.8, p<0.001$, df $=8$ ).

We now consider the predictive performance of the local rate-maximization model. The predicted mean delay at the fixed feeding site according to the equations of the local rate-maximization model was $6.1 \mathrm{~s}$, a value that was shorter than the observed adjusting delay (combined one sample $t$-tests, $\chi^{2}=17.5, p<0.05, \mathrm{df}=8$ ). The comparison between model prediction and pooled data is shown in Fig. 4.

\section{Discussion}

Our aim was to assess the effects of energy budget on coal tits' preferences for variability in delay to food. We tested the subjects' preferences between a variable feeding option ( 3 or $30 \mathrm{~s}$ with probability 0.5 ) versus an adjusting option (16.5 s initially; changed $\pm 10 \%$ repeatedly until indifference for foraging option was achieved), under both positive and negative energy budgets. The experiment was designed as a direct test of the budget rule 
(Stephens, 1981), which states that an animal should be risk prone on negative energy budget and risk averse on positive energy budget. Our results supported this rule to some extent because risk preference significantly accentuated from positive to negative energy budgets. In agreement to the budget rule, our subjects were significantly risk prone when energy budget was negative. However, we did not find full support for the energy budget rule because coal tits were also risk prone when their energy budget was positive.

Risk-sensitive preferences in birds have been tested before (see review in Kacelnik \& Bateson, 1996; Brito \& Kacelnik, 1999), and the most frequent result has been a strong tendency toward risk proneness when variability was caused by delay to food, and weak risk aversion when variability was caused by amount of food. Direct tests of the energy budget rule were, however, scarce and none of them tested risk-sensitive foraging when variability was caused by delay to food in birds smaller than $60 \mathrm{~g}$ (Fig. 3 in Kacelnik \& Bateson, 1996). The only study of risk-sensitive foraging in birds smaller than $10 \mathrm{~g}$ was about variability in amount to food, and it reported no effect of budget manipulation (Barkan, 1990). Few studies have manipulated budget while testing risk-sensitive foraging when variability was caused by delay to food (Kacelnik \& Bateson, 1996; Bateson \& Kacelnik, 1997), and only one study reported a partial change in preference (Reboreda \& Kacelnik, 1991). Although Reboreda \& Kacelnik did not manipulate the energy budget directly, because their main goal was to compare risk preferences between amount and time variability, their results confirmed the trend toward strong risk proneness for delay. Using inter-individual differences on intake rates, Reboreda \& Kacelnik found a positive correlation between intake rate (i.e. energy budget) and risk aversion (see Fig. 5 in Reboreda \& Kacelnik, 1991), with an overall preference for the variable option when variability was in delay to food.

Our controlled conditions allowed us to confirm the correlational observation of Reboreda \& Kacelnik. With a small decrease in air temperature, we were able to induce a negative energy budget. To induce an energy stress we decreased the air temperature by $10^{\circ} \mathrm{C}$, from 24 to $14^{\circ} \mathrm{C}$, and removed most bird's mechanisms of cold defense (Dawson \& O'Connor, 1996) such as insulation, behavioural thermogenesis, and endogenous heat production. Heat increment could be also obtained by feeding, and indeed there was an 
increase in daily intake that counterbalanced to some extent the negative energy budget induced when air temperature was decreased. The main evidence that coal tits were under energy stress was that body mass decreased at low air temperature. Birds tried to compensate the negative energy budget by being less active and increasing their daily food intake. The decrease in the latency to peck for food showed that birds were more motivated to peck quickly, being also another evidence that birds were in a negative energy budget.

Previous failures of the budget rule predictions in birds may have been to some extent due to the size and biology of the experimental subjects. All bird studies reporting a lack of change in the preference for variability in delay to food were performed in relative large species ( $>60 \mathrm{~g}$, Kacelnik $\&$ Bateson, 1996). Increasing budget manipulations to show a change in risk proneness would work in small or very small birds species mainly, because small birds may have evolved to be risk-sensitive (Kacelnik \& Bateson, 1996). The condition s favoring risk-sensitive foraging may increase as body size decreases, because small body reserves cannot counteract food unpredictability. Flexibility in risk attitude leads to higher fitness, although the benefits are very small (McNamara, 1996). If risk-sensitive foraging offer small but greater benefits than risk-insensitive foraging, some effect of budget manipulation may be found in the small birds species, and hardly in the big species. A comparative analysis of risk-sensitive foraging across bird species may settle the body mass effect in risk attitude, but such analysis has not been done yet (Kacelnik \& Bateson, 1996; Brito \& Kacelnik, 1999). Our study contributes to fill the need of studies about risk-sensitive foraging with very small bird species, and offer support for such comparative analysis.

Alternatively to the predictions of the energy budget rule, we also compared the observed risk proneness with the prediction of a short-term foraging model: the expectation of the ratios model ('EoR', see Bateson \& Kacelnik, 1996). In this model subjects compute intake rate averaging the ratio of gain to time on a per-trial basis rather than on a per-time basis, and this leads to deviations from overall rate maximization. This model predicts risk proneness when variability is in delay. In the fixed feeder the adjusting delay was longer than the predicted by the EoR model in both treatments. The fact that coal tits increased their preference for the variable option in the negative energy budget nearly to the delay predicted by the short-term foraging model may be signaling only that foragers do well, but that they do not optimize 
most of the time. Animals optimize foraging behaviour mainly when there is a short-fall in food availability (Myers, 1983; Krebs \& McCleery, 1984; Stephens \& Krebs, 1986). Indeed it is a commonly observed fact that energymaximising models work better when animals are hungrier (Kacelnik, 1987). Coal tits may had somehow relaxed their discriminant efforts between feeding alternatives in the positive energy budget, and estimated more accurately the relative intake rates between the variable and fixed foraging options when their energy budget was negative. Although there was also a significant difference between predicted and observed delays in the negative energy budget treatment, we are reluctant to diminish the EoR model predictive role as it offers a plausible heuristic explanation of animal foraging (Bateson \& Kacelnik, 1996; Bateson \& Whitehead, 1996), and may be used as an alternative model to the energy budget rule in foraging behaviour studies.

In this study we compared our results mainly to the predictions of the energy budget rule. However, risk sensitive foraging has been characterised by a multiplicity of approaches and theories, being the local rate maximisation model one of them. Other competing approaches such as scalar expectancy theory (Gibbon et al., 1988; Kacelnik \& Brito e Abreu, 1998) and time discounting (Kagel et al., 1986; Myerson \& Green, 1995) provide alternative explanations to the energy budget rule, but none of the available theories (energy budget rule included) adequately accounts for all the crucial behavioural observation s recently gathered (Smallwood \& Cartar, 1996).

In conclusion, we found that coal tits living in positive and negative energy budgets were persistently risk prone when there was variability in delay to obtain food. It is noteworthy that this preference was strongest in the negative energy budget, as predicted by the energy budget rule. This result may be favoured by the small body size of the bird species selected. Further experiments with small or very small birds are needed to clarify the relationship between body size and risk-sensitive foraging in a comparative study between several bird species.

\section{References}

Aulie, A. \& Tøien, Ø. (1989). Shivering in aerobic and anaerobic muscles in bantams (Gallus domesticus). - In: Physiology of cold adaptations in birds (C. Bech \& R.E. Reinertsen, eds). Plenum Press, New York, p. 77-82.

Barkan, C. (1990). A field test of risk-sensitive foraging in black-capped chickadees (Parus atricapillus). — Ecology 71, p. 391-400. 
Bateson, M. \& Kacelnik, A. (1996). Rate currencies and the foraging starling: the fallacy of the averages revisited. - Behav. Ecol. 7, p. 341-352.

— — \& — - (1997). Starlings preferences for predictable and unpredictable delays to food. - Anim. Behav. 53, p. 1129-1142.

— — \& Whitehead, S.C. (1996). The energetic costs of alternative rate currencies in the foraging starling. - Ecology 77, p. 1303-1307.

Brito, F. \& Kacelnik, A. (1999). Energy budgets and risk-sensitive foraging in starlings. Behav. Ecol. 10, p. 338-345.

Caraco, T., Martindale, S. \& Whittam, T.S. (1980). An empirical demonstration of risksensitive foraging preferences. - Anim. Behav. 28, p. 820-830.

CeNeS Cognition, L. (1990). Arachnid. 1.0. Cambridge, UK.

Collier, G.H. (1983). Life in a closed economy: the ecology of learning and motivation. In: Advances in the analysis of behavior (M.D. Zeiler \& P. Harzem, eds). Chichester, UK, p. 223-274.

Dawson, W.R. \& O'Connor, T.P. (1996). Energetic features of avian thermoregulatory responses. - In: Avian energetics and nutritional ecology. (C. Carey, ed.). Chapman and Hall, New York, p. 85-157.

Dunning, J.B. \& Church, R.M. (1993). CRC Handbook of avian body masses. — Boca Raton, Florida.

Gibbon, J., Church, R.M., Fairhurst, S. \& Kacelnik, A. (1988). Scalar expectancy theory and choice between delayed rewards. - Psychol. Rev. 95, p. 102-114.

Hursh, S.R. (1980). Economic concepts for the analysis of behaviour. - J. Exp. Anal. Behav. 34, p. 219-238.

Kacelnik, A. (1987). Information primacy or preference for familiar foraging techniques? A critic of Inglish \& Ferguson. - Anim. Behav. 35, p. 925-926.

— — \& Bateson, M. (1996). Risky theories: The effects of variance on foraging decisions. - American Zool. 36, p. 402-434.

— — \& Brito e Abreu, F. (1998). Risky choice and Weber's Law. — J. theor. Biol. 194, p. 289-298.

Kagel, J.H., Green, L. \& Caraco, T. (1986). When foragers discount the future: constraint or adaptation? - Anim. Behav. 34, p. 271-283.

Krebs, J.R. \& McCleery, R.H. (1984). Optimization in behavioural ecology. — In: Behavioural ecology: An evolutionary approach (J.R. Krebs \& N.B. Davies, eds). Sinauer Associates, Sunderland, p. 91-121.

Marsh, R.L. (1993). Does regulatory nonshivering thermogenesis occur in birds? — In: Life in the cold (C. Carey, G. L. Florant, B. A. Wunder \& B. Horwitz, eds). Westview Press, Boulder, Colorado, p. 535-538.

— — \& Dawson, W.R. (1989). Avian adjustment to cold. — In: Advances in comparative and environmental physiology (L.C.H. Wang, ed.). Springer Verlag, Berlin, p. 205-253.

Mazur, J.E. (1984). Tests of an equivalence rule for fixed and variable reinforcer delays. J. Exp. Psychol. Anim. Behav. Proc. 10, p. 426-436.

McNamara, J. (1996). Risk-prone behaviour under rules which have evolved in a changing environment. - American Zool. 36, p. 484-495.

Myers, J.P. (1983). Commentary. - In: Perspectives in ornithology (A.H. Brush \& G.A. Clark, eds). Cambridge University Press, New York, p. 216-221.

Myerson, J. \& Green, L. (1995). Discounting of delayed rewards: Models of individual choice. - J. Exp. Anal. Behav. 64, p. 263-276. 
Reboreda, J.C. \& Kacelnik, A. (1991). Risk sensitivity in starlings: variability in food amount and food delay. - Behav. Ecol. 2, p. 301-308.

Smallwood, P.D. \& Cartar, R.V. (1996). Risk sensitivity in behavior: where are we now? Introduction to the symposium: Risk sensitivity in behavioural ecology. - Am. Zool. 36, p. 389-391.

Sokal, R.R. \& Rholf, F.J. (1981). Biometry. — Freeman, New York.

Staddon, J.E.R. (1983). Adaptive behavior and learning. — Cambridge University Press, New York.

Stephens, D.W. (1981). The logic of risk-sensitive foraging preferences. - Anim. Behav. 29, p. 628-629.

— — \& Krebs, J.R. (1986). Foraging theory. — Princeton University Press, Princeton. 